\title{
Conformational Change of Ovalbumin Induced by Surface Cavity Binding of N-Phthaloyl Gamma-Aminobutyric Acid Derivative: a Study Theoretical and Experimental
}

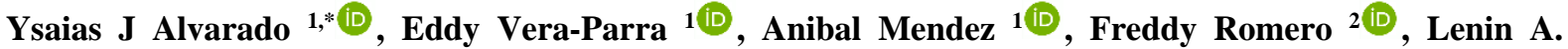 \\ Gonzalez-Paz $^{3 \mathbb{C}}$, Luis S. Moncayo ${ }^{4 \mathbb{D}}$, Jelem Restrepo ${ }^{5(\mathbb{D})}$, Patricia Rodríguez-Lugo ${ }^{6}{ }^{\mathbb{D}}$, \\ José Luis Paz ${ }^{7(\mathbb{D})}$, Joan Vera-Villalobos ${ }^{8 *} * \mathbb{D}$
}

1 Centro de Investigación y Tecnología de Materiales (CITeMA), Laboratorio de Caracterización Molecular y Biomolecular (LCMB), Instituto Venezolano de Investigaciones Científicas (IVIC), Maracaibo, Estado Zulia, República Bolivariana de Venezuela

2 Baylor College of Medicine, Texas University, USA

3 Laboratorio de Genética y Biología Molecular (LGB). Departamento de Biología, Facultad Experimental de Ciencias, República Bolivariana de Venezuela

4 Universidad Católica de Cuenca. Unidad Académica de Salud y Bienestar, Farmacia, Laboratorio de Microbiología, Ecuador

5 Centro de Investigación y Tecnología de Materiales (CITeMA), Laboratorio Investigación de Síntesis Sustentable de Nuevos Materiales (LISSDeNUMA), Instituto Venezolano de Investigaciones Científicas (IVIC), Maracaibo, Estado Zulia, República Bolivariana de Venezuela

6 Laboratorio de Electrónica Molecular, Departamento de Química, Facultad Experimental de Ciencias, República Bolivariana de Venezuela

7 Escuela Politécnica Nacional, Departamento de Física, Ladrón de Guevara, E11-253, 170517, Quito-Ecuador

8 Escuela Superior Politécnica del Litoral, ESPOL, Facultad Experimental de Ciencias Naturales y Matemáticas, Departamento de Química y Ciencias Ambientales, Ecuador

* Correspondence: joarvera@espol.edu.ec (J.V) ; alvaradoysaias@gmail.com (Y.A);

Scopus Author ID 36678130400

Received: 17.08.2020; Revised: 10.09.2020; Accepted: 12.09.2020; Published: 15.09.2020

Abstract: In this work is reported the study of the interaction between ovalbumin protein (OVA) and $\mathrm{N}-\mathrm{Phthaloyl}$ gamma-aminobutyric acid derivative (NPG). The ovalbumin is a kind of globular protein present in chicken eggs, as part of serpins globular family proteins present in many biological systems and natural environment; is commonly used in the food industry and the pharmaceutical field as an alternative material for microencapsulation of water-soluble drugs. However, this egg protein has discrete binding sites for ligands as occur in their homologs in mammalian. Association constants and thermodynamic parameters for the interaction of OVA with PNG were determined by linear and 2D fluorescence techniques, zeta-potential, acoustic densimetry, molecular modeling (docking), and molecular dynamics simulations in water as solvent at physiological $\mathrm{pH}$. Fluorescence quenching of the internal fluorophore (tryptophan/tyrosine) in the range of temperature $296.15 \mathrm{~K}-308.15 \mathrm{~K}$ resulted in values for the association constants of the order of $10^{3} \mathrm{~L} \mathrm{~mol}^{-1}$, indicating an interaction between the NPG and the albumin. The negative values of $\Delta \mathrm{G}^{\circ}$ indicate a spontaneous process; $\Delta \mathrm{H}^{\circ}$ is positive indicates an endothermic process of association, and $\Delta \mathrm{S}^{\circ}$ is positive, and $\mathrm{T} \Delta \mathrm{S}^{\circ}$ is the dominant term, which shows that the interaction is mainly due to hydrophobic factors, although, other experimental techniques suggest contributions from neutralization charge and hydrogen bonds there is also. The binding of NPG induced changes in OVA protein spatial conformation. The results of fluorescence and acoustic densimetry showed that the interaction promoted the unfolding of protein with a modest increase in the molar partial volume and loss of water molecules. The fluorescence quenching occurs through a static mechanism. Molecular docking and molecular dynamics simulations studies support that NPG can interact with OVA accommodated in a superficial cavity involving hydrophobic forces and hydrogen bonds. The generally accepted criterion about the dependence of Stern-Volmer constant with temperature for a dynamic mechanism is not rigorous and should be handled with caution. 
Keywords: Ovalbumin; Binding Studies; Spectroscopic Study; Molecular Modeling Docking; Molecular Dynamic.

(C) 2020 by the authors. This article is an open-access article distributed under the terms and conditions of the Creative Commons Attribution (CC BY) license (https://creativecommons.org/licenses/by/4.0/).

\section{Introduction}

Globular Proteins such as ovalbumin (OVA), bovine serum albumin (BSA), and human serum albumin (HSA) have been widely used as models to evaluate interactions between ligand and proteins [1-3]. In the case of OVA, it consists of a single polypeptide chain of 385 amino acid residues that folds into a globular conformation [4]. It is known that this chicken protein has discrete binding sites for ligands as occur in their homologs in mammalian [5]. This protein present in many biological systems and natural environments; is commonly used in the food industry $[3,5,6]$, most recently, in the pharmaceutical field, as an alternative material for microencapsulation of water-soluble drugs $[3,7]$.

Between the many challenges involved in the implementation of proteins in formulations, the main one is the complete understanding of their physic-chemical and biological stability alongside with their pharmacokinetic properties [8,9]. It is well known that the chemical and conformational stability of proteins can be compromised by external factors such as changes in $\mathrm{pH}$, temperature, and surface interaction with ligands or co-solvents, among others.

In recent years, has been reported studies about the interactions of different kinds of drugs and small molecules with proteins, involving a full set of spectroscopic techniques like UV-Visible, fluorescence and 3D fluorescence, dynamic light scattering, circular dichroism, and Fourier transform infrared, or computational tools as molecular docking [1-3,10], all to characterize the functional properties, denaturalization, hydration and conformational changes of the proteins and their complex. These studies open opportunities for understanding and take advantage of the structure of biological macromolecules as a carrier of drug and bioavailability. Recently, OVA has attracted attention due to its capacity to bind both hydrophobic and hydrophilic ligands and antibiotics [11-13], and thus, this globular protein OVA has proposed too as a macromolecular carrier for improving the solubility and stability of insolubility bioactive molecules[14]. Thus, the study of the interaction of this model protein with ligands of a variety of chemical structures and polarities is of great interest within biophysical chemistry[10].

Therefore, we reported in this work the conformational changes in OVA-induced by the interaction with N-Phthaloyl gamma-aminobutyric. N-Phthaloyl gamma-aminobutyric acid derivative (henceforth denoted as NPG; see Fig.1) [15,16], which recently has reported as an agent that offers protection by regulation of the levels of the lipid peroxidation products, antioxidants, and liver markers during light constant (LL)-exposed stress in rats. We have employed fluorescence spectroscopy, laser doppler velocimetry, acoustic densimetry in conjunction with molecular docking and molecular dynamics calculations to characterize the binding of NPG to OVA at 1 atm, pH 6.8 over a temperature range of $293.15 \mathrm{~K}$ and $308.15 \mathrm{~K}$.

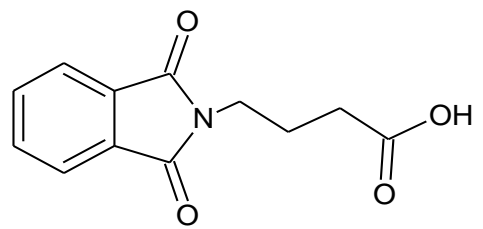

Figure 1. N-Phthaloyl gamma-aminobutyric acid derivative (NPG). 


\section{Materials and Methods}

\subsection{Materials.}

$\mathrm{N}$-Phthaloyl gamma-aminobutyric acid derivate used in this work were synthesized by direct condensation reaction between anhydride phthalic and gamma-aminobutyric acid following the procedure previously reported $[15,16]$. Ovalbumin (OVA) with molar mass $\mathrm{M}_{2}$ of $45 \mathrm{kD}$ was purchased from Sigma Aldrich. Free-salt solutions of the protein were prepared using distilled and ultra-purified water (18 $\mathrm{M} \Omega$ resistance). For all experiments here realized, the concentration of the protein was determined by UV-Vis spectroscopy using the value of the molar absorption coefficient reported in the literature $[17,18]$. The $\mathrm{pH}$ values of the solutions prepared fluctuated very close to neutral $\mathrm{pH}(6.8)$.

\subsection{Apparatus and methods.}

2.2.1. Ultraviolet, visible spectroscopy studies.

The UV-Vis spectrum of protein, NPG, and their mixtures were measured using water as a reference in a spectrophotometer Shimadzu model UV-3101PC and using $1 \mathrm{~cm}$ quartz cells. The temperature was kept constant at $298.15 \mathrm{~K}$ with a Peltier effect based thermostatic unit Shimadzu CPS-260, and the working wavelength range was set between 220 and $500 \mathrm{~nm}$.

\subsubsection{Fluorescence studies.}

All fluorescence spectra in steady-state of protein and their mixture with NPG in freesalt water were recorded on an RF-5301PC spectrofluorophotometer (Shimadzu), coupled to a PC and equipped with an electronic thermal regulating water-bath for controlling the temperature. $1.0 \mathrm{~cm}$ quartz cells were used for the measurements. A solution of OVA (2.06 $\mathrm{x} 10^{-5} \mathrm{M}$ ) was titrated by the successive addition of NPG; this was realized following the usual method [19]. The excitation wavelengths were set to $280 \mathrm{~nm}$, and the emission spectra in each experiment were recorded from 220 to $500 \mathrm{~nm}$. All measurements were performed over a temperature range of $293.15 \mathrm{~K}$ and $308.15 \mathrm{~K}$. The correction based in the inner filter effect was considered in these measurements. The excitation and emission slit widths were $5 \mathrm{~nm}$ [3]. These fluorescence intensity data were utilized to evaluate the quenching mechanism operative in this system in terms of the Stern-Volmer model [20].

Synchronous fluorescence spectra were recorded from 220 to $500 \mathrm{~nm}$ when the value was fixed to $\Delta \lambda=15 \mathrm{~nm}$ and $\Delta \lambda=60 \mathrm{~nm}$ for tyrosine and tryptophan, respectively. A study of 3D fluorescence was carried out with initial excitation wavelength from 220 to $390 \mathrm{~nm}$ with increments of $5 \mathrm{~nm}$, while the emission was recorded in the wavelength range from 220 to 500 $\mathrm{nm}$ with a slit width of $5 \mathrm{~nm}$ in all cases. The number of spectra scanned was 56 in each case.

\subsubsection{Volumetric studies.}

The densities $\rho$ and ultrasound velocities $v_{\text {s }}$ of solutions as well as the solvent density $\rho_{1}$ and $v_{1}$, respectively, were determined at the temperature of $298.15 \mathrm{~K}$ and $1 \mathrm{~atm}$ of pressure using a variable-temperature Anton-Paar acoustic densitometer DSA-5000, calibrated before each series of measurements with bi-distilled, deionized (18 M $\Omega$ resistance) and degassed water and dry air. Each value reported of density is an average of five measurements. The limiting partial molar volume $\mathrm{V}_{2}{ }^{\infty}$ of OVA $\left(\mathrm{M}_{2}=45 \mathrm{kDa}\right)$ in the presence and absence of NPG 
were estimated from the measured densities following two procedures [21-23]: 1) as the average value of the partial molar volume determined with the eq. 1 within the investigated concentration range (from $1 \times 10^{-3}$ to $1 \times 10^{-4} \mathrm{M}$ ); and 2) from Redlich's equation of two terms (eq.2) using the method of least squares (the experimental values are shown in Table S1 of the supplementary material).

$$
\begin{aligned}
& V_{2, \varnothing}=\frac{M_{2}}{\rho_{1}}-10^{3}\left(\frac{\rho-\rho_{1}}{\rho_{1} C_{2}}\right) \\
& \rho=\rho_{1}+\Gamma C_{2} \begin{array}{l}
M_{2}-\rho_{1} V_{2}^{\infty} \\
10^{3}
\end{array}
\end{aligned}
$$

The concentration of NPG was fixed to $1 \times 10^{-3} \mathrm{M}$ in these experiments.

The adiabatic compressibility of each solution (ks) and solvent (ki) were determined using the Newton-Laplace's equation (the values of these quantities can be seen in the Table $\mathrm{S} 2$ in supplementary material) [24,25].

$$
\kappa_{i}=\frac{1}{U_{i}^{2} \rho_{i}} \quad i=S, 1
$$

The hydration number at each concentration of protein in the presence or absence of NPG was estimated using the acoustic Pasynski method (where $n_{1}$ and $n_{\text {solute }}$ is the amount (mol) of solvent and solute, respectively) [24].

$$
n_{h}=\frac{n_{1}}{n_{\text {solute }}}\left(1-\frac{\kappa_{s}}{\kappa_{1}}\right)
$$

The hydration number of the protein at infinite dilution was estimated as the mean value of the values obtained of nh. Alternatively, this quantity was calculated using the relation,

$$
n_{h}=-\frac{1}{\kappa_{1}}\left(\frac{d \kappa_{s}}{d x_{2}}\right)_{x_{2} \rightarrow 0}
$$

Here $\mathrm{X}_{2}$ is the solute mole fraction.

\subsubsection{Zeta-potential measurements (Laser Doppler Velocimetry).}

The zeta potential was measure at $298.15 \mathrm{~K}$ using a U-folded capillary cell and a Zetasizer (Nano-ZS) from Malvern Instruments and using the Laser Doppler Velocimetry technique [26]. The concentration of protein was fixed to $1.65 \times 10^{-5} \mathrm{M}$ and titrated by the successive addition of NPG (from $1.1 \times 10^{-4}$ to $6.1 \times 10^{-4} \mathrm{M}$ ).

2.2.5. Molecular modeling (docking) and molecular dynamics study.

The structure of Ovalbumin obtained from the RCSB protein database (PDB ID: 1OVA) was used in this study. The 2D structure of the NPG compound (figure 1) was built using the SwissADME web server tools and was obtained in SMILES format (http://www.swissadme.ch/), and then the SMILES online converter was used (https: //cactus.nci.nih.gov/translate/) to get a PDB format of the structure. To simulate ligand-protein binding, complexes were constructed and compared with the DockThor server 
(https://dockthor.lncc.br/v2/) using the flexibility algorithm, blind docking, and DockT function calculation. To increase the precision, 25 runs were performed with 106 evaluations per run. The COACH-D server was too use, also using blind docking and the calculation of the AutoDock Vina (ADV) scoring function. The most favored positions were further analyzed with MMV_2019_7.0.0, calculating the MolDock, Rerank, and PLANTS functions.

\subsubsection{Molecular Dynamics (MD).}

To the structure preparation, the X-ray structure of the A-chain of the OVA was recovered, and the SymmDock algorithm (http://bioinfo3d.cs.tau.ac.il/SymmDock/) was used and also it was compared to the HSYMDOCK server (http://huanglab.phys.hust.edu.cn/hsymdock/) for the prediction of missing protein atoms by constructing complexes based on symmetry and geometry. The fully prepared structure was used for the subsequent analysis of MD. The simulations were carried out with two purposes: 1) to study the relative stability of the complex formed by the ligand docking to the protein structure, and 2) sample a set of conformations for structural disturbance analysis. A simulated complex consisted of one copy of the protein structure, one copy of the docked ligand, and 50 $\mathrm{Na}^{+}$and $\mathrm{Cl}^{-}$ions to simulate physiological conditions. The entire system was neutralized. For a protein-ligand complex, the system was first relaxed through a series of minimization procedures. There were three phases for the simulation: 1) relaxation, 2) equilibrium, and 3) sampling, in which the system progressively heated and equilibrated as recommended [27]. Simulations were performed at $100 \mathrm{~ns}$ and 4 ns. All MD simulations and additional configurations were performed with the myPresto program [28].

\section{Results and Discussion}

\subsection{Ultraviolet, visible spectroscopy.}

Fig 2 is shown that the UV-Vis absorption spectrum for OVA protein in the presence of NPG in water in the spectral region from 260 to $380 \mathrm{~nm}$ is overlapped very well within error experimental with the spectrum obtained as the sum of the individual spectrum of NPG and OVA.

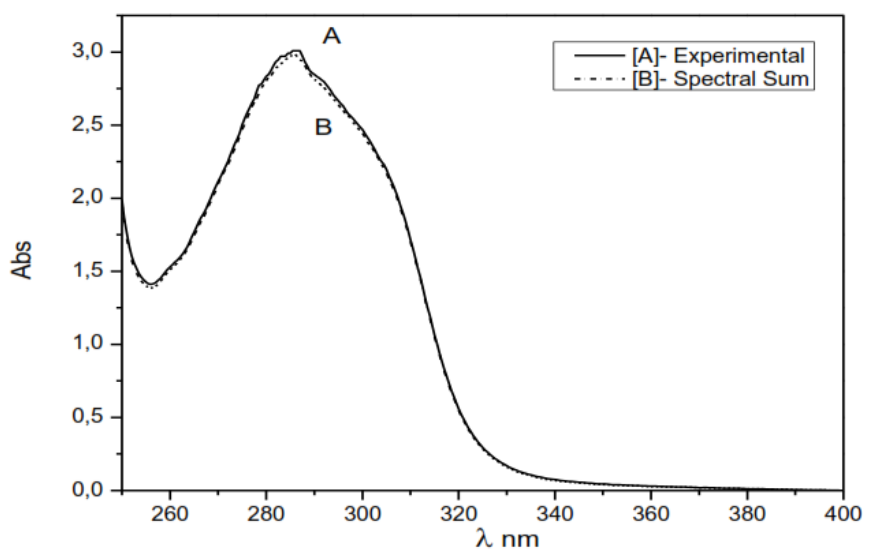

Figure 2. UV-Vis overlapping of the experimental mixture of OVA and NPG (A) and the sum of individual spectra for NPG and OVA (B) Mix OVA-NPG carried out in the water.

It is known that the change in the shape, intensity, and shift of electronic bands of globular proteins is generally observed when the spatial conformational of protein is significantly affected because to the formation of a complex via strong binding of a ligand to 
the internal cavity of the protein [3,29-31]. And then, our result suggests that no, there is the formation of a ground-state complex with OVA by covalent binding of NPG, as is expected for a static mechanism [32]. Unfortunately, in the spectrum range from 200 to $230 \mathrm{~nm}$ were the contributions of the $\alpha$-helix structure of OVA is very important for the detection of the interaction with ligands that induce structural perturbation of protein [3]; NPG also has high absorption in this same region and it impossibility carried out the quantitative measure of spectral changes induced in this region without ambiguity. As a consequence, perturbations in the peptide strand and tridimensional structure of OVA by binding of the ligand and the corresponding formation of a complex OVA-NPG cannot be refused totally for the results obtained with this experimental way.

\subsection{Quenching, binding.}

Figure 3 shows the behavior of the fluorescence emission band the following excitation at $280 \mathrm{~nm}$ of OVA with various amounts of NPG. The fluorescence intensity of this protein decreased upon increasing the concentration of NPG. But under good experimental quencher, which appreciably induced a decrease of the fluorescence intensity of OVA as a consequence of that NPG bond to OVA. It is important to mention that NPG derivative has not intrinsic fluorescence under the present experimental conditions. As a consequence, the emission spectra observed is due to the intrinsic fluorescence of protein (OVA), which has its origin in the fluorescence overlapped of the tryptophan (Trp) and tyrosine (Tyr) residues [33]. In order to evaluate the quenching mechanism, the fluorescence quenching data at four different temperatures were analyzed following the Stern-Volmer equation [20,33].

$$
\frac{F_{0}}{F}=1+K_{S V}[Q]
$$

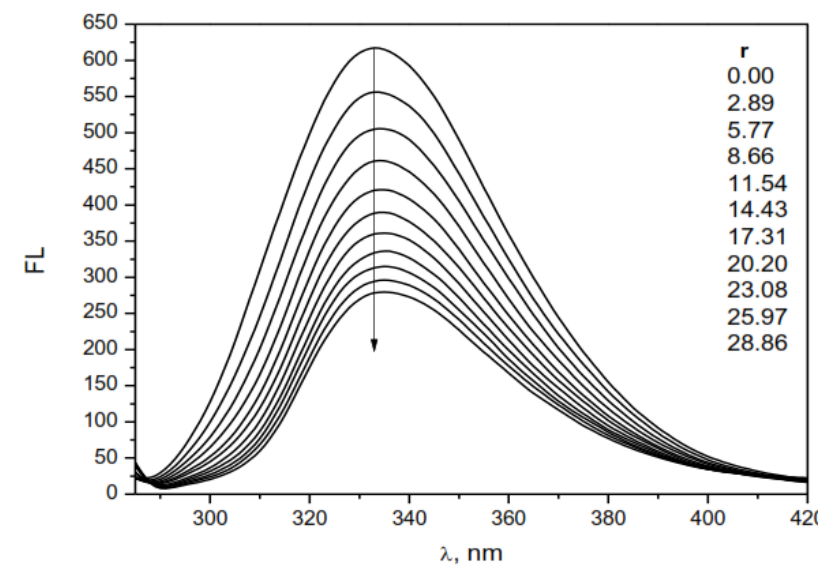

Figure 3. Fluorescence spectrum of OVA $\left[2.06 \times 10^{-5} \mathrm{M}\right]$ vs NPG $\left[1.19 \times 10^{-3} \mathrm{M}\right]$ at $298.15 \mathrm{~K}$ and excitation 280 $\mathrm{nm}(\mathrm{r}=[\mathrm{NPG}] /[\mathrm{OVA}])$.

In this equation, $\mathrm{F}_{0}$ and $\mathrm{F}$ are the fluorescence of protein in the absence and presence of quencher, respectively; [Q] is the total concentration of quencher (NPG derivative), and Ksv is the Stern- Volmer quenching constant. This constant is equal to the product of quenching rate constant for the biomolecule $\left(\mathrm{K}_{\mathrm{q}}\right)$ and average time of the excited state of the protein without quencher $\tau_{0}\left(\sim 10^{-8} \mathrm{~s}\right)[20]$.

In the Fig. 4 is shown the plot of the fluorescence relative ( $\left.\mathrm{F}_{0} / \mathrm{F}\right)$ vs [Q] at different temperatures. In this figure can be seen clearly that at each temperature, a linear Stern-Volmer 
plot was obtained [20,33]. From these experimental data and the application of the least- square method was possible to determine the values of $\mathrm{K}_{\mathrm{sv}}$ and $\mathrm{K}_{\mathrm{q}}$ which can be seen in Table 1 .

The tendencies of $\mathrm{K}_{\mathrm{sv}}$ with the temperature are indicative of the quenching mechanism that is operative within our system. As can be seen in Table 1, the magnitude of $\mathrm{K}_{\mathrm{sv}}$ and $\mathrm{K}_{\mathrm{q}}$ increase as an increase in the temperature, which suggests that a dynamic quenching mechanism is in play and that this mechanism only affects the excited state with no changes in the fundamental electronic state $[3,34]$. However, it is very important to note that for a dynamic quenching mechanism from diffusion or bimolecular collision, the limiting value of $\mathrm{K}_{\mathrm{q}}$ is about $10^{10} \mathrm{Lmol}^{-1} \mathrm{~s}^{-1}$. Interestingly, the values obtained in this work for $\mathrm{K}_{\mathrm{q}}$ are higher than that of $10^{10}$ $\mathrm{L} \mathrm{mol}^{-1} \mathrm{~s}^{-1}$, which indicate a contribution from the static mechanism, and suggest that the formation of a non-fluorescent complex is more relevant in this mechanism rather than the dynamic collision [35].

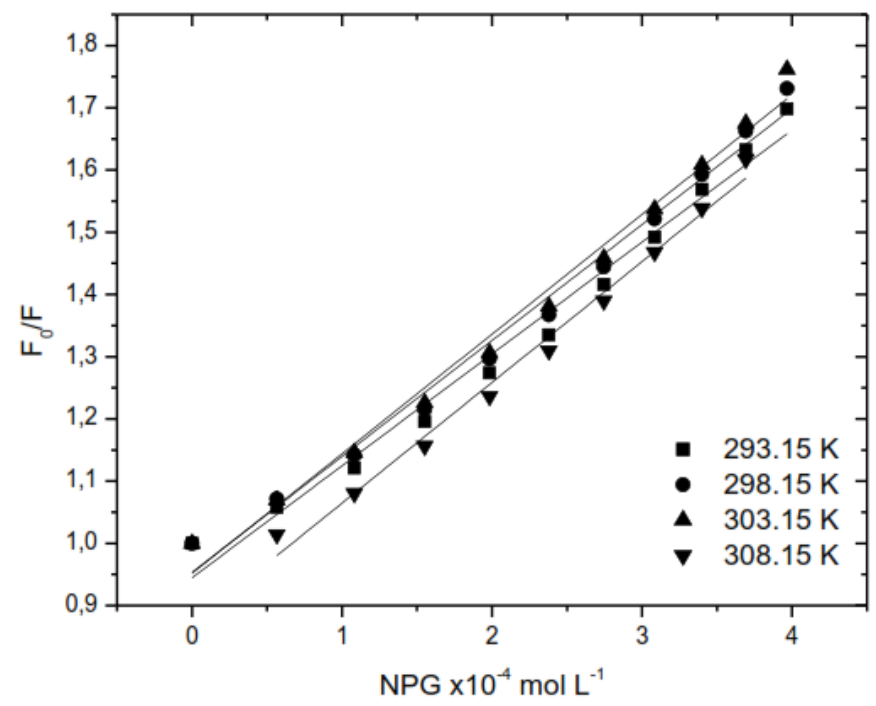

Figure 4. Stern-Volmer analysis for NPG-OVA system at 293.15-308.15 K and $1 \mathrm{~atm}$.

Table 1. Stern-Volmer and Quenching constant for NPG-OVA system at $\lambda_{\mathrm{ex}}=280 \mathrm{~nm}, 293.15$ to $308.15 \mathrm{~K}$, and $1 \mathrm{~atm}$.

\begin{tabular}{c|c|c|c}
\multirow{2}{*}{$\mathbf{T}, \mathbf{K}$} & $\mathbf{K}_{\mathbf{s v} \mathbf{X 1 0}} \mathbf{3}^{\mathbf{3}}$ & $\mathbf{K}_{\mathbf{q} \mathbf{x} \mathbf{1 0}^{\mathbf{1 1}}}$ & $\mathbf{R}^{\mathbf{2}}$ \\
\cline { 2 - 4 } & $\mathbf{\mathbf { ~ m o l } ^ { \mathbf { 1 } }}$ & $\mathbf{\mathbf { ~ m o l } ^ { \mathbf { 1 } } \mathbf { s } ^ { \mathbf { 1 } }}$ & \\
\hline 293.15 & 1.80 & 1.80 & 0.9833 \\
\hline 298.15 & 1.86 & 1.86 & 0.9878 \\
\hline 303.15 & 1.92 & 1.92 & 0.9881 \\
\hline 308.15 & 1.94 & 1.94 & 0.9902
\end{tabular}

\subsection{Conformational study.}

In order to separate the overlapped excitation of Trp and Tyr residues and evaluate the change that occurs in the micro-environment of these amino acid residues induced by binding of NPG, we carried out studies based in synchronous fluorescence spectroscopy [36]. With this type of spectroscopy, is possible to simultaneously scan the excitation $\left(\lambda_{\mathrm{ex}}\right)$ and emission $\left(\lambda_{\mathrm{em}}\right)$ monochromators while maintaining a constant wavelength interval between them [36] to the distinction between the optical response of different chromophores and detecting changes of the polarity in the vicinity of the residues in the protein, following this difference $\Delta \lambda=\lambda_{\text {em }}-\lambda_{\text {ex }}$ [36,37].

In the case of globular proteins, through the analysis of $\Delta \lambda$ is possible to detect the changes in the dielectric environment (micro-polarity) around of the $\operatorname{Trp}(\Delta \lambda=60 \mathrm{~nm})$ and $\operatorname{Tyr}$ 
$(\Delta \lambda=15 \mathrm{~nm})$ residues due to conformational changes of protein induced by binding of ligand[36-38].
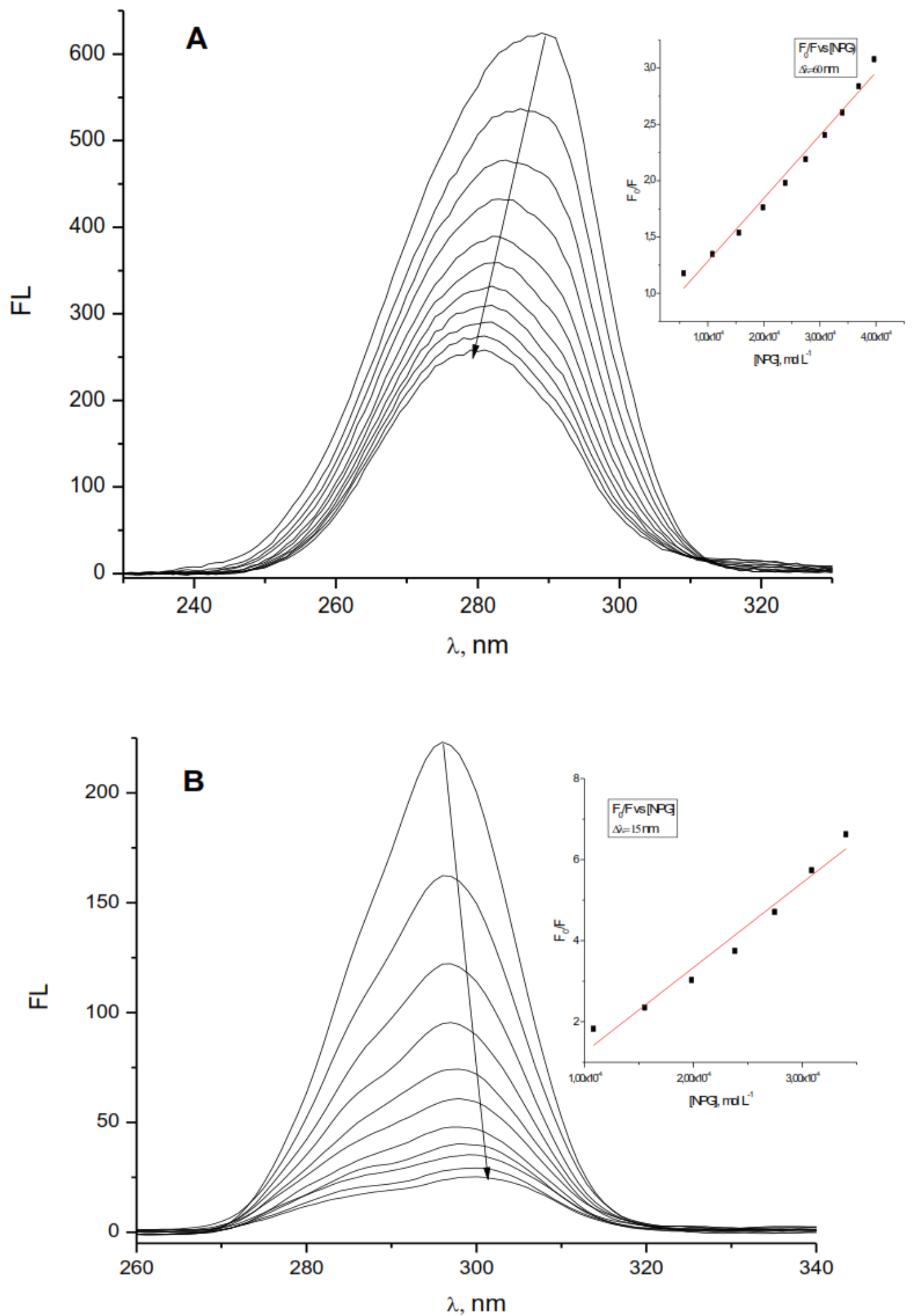

Figure 5. (A) Synchronous fluorescence at $\Delta \lambda=60 \mathrm{~nm}$ for tryptophan residue in the OVA-NPG system. (B) Synchronous fluorescence at $\Delta \lambda=15 \mathrm{~nm}$ for tryptophan residue in the OVA-NPG system.

In the Fig $5 \mathrm{~A}$ can be observed that the addition of NPG to OVA when $\Delta \lambda$ was set to $60 \mathrm{~nm}$ at $298.15 \mathrm{~K}$, led to a great decrease in the synchronous fluorescence intensity of $\operatorname{Trp}$ residues of this protein, and a blue-shifted $(\sim 10 \mathrm{~nm})$ in the emission maxima can be observed too. 

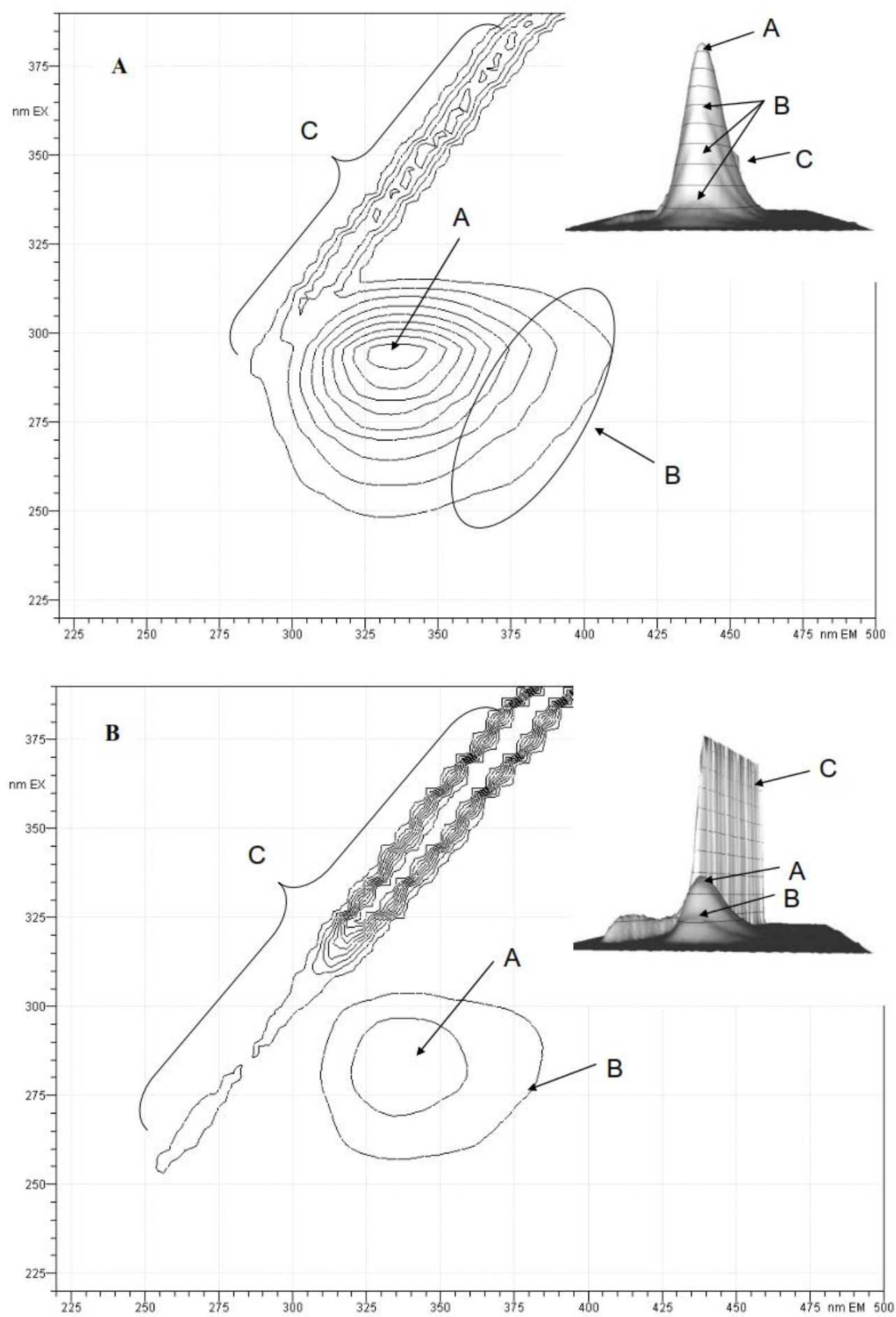

Figure 6. (A) 3D Graphic for OVA $2.06 \times 10^{-5} \mathrm{M}$ without NPG. (B) 3D Graphic for OVA 2.06x $10^{-5} \mathrm{M}$ in the presence of NPG $1.19 \times 10^{-3} \mathrm{M}$.

This result suggests that the environment in the vicinity of Trp residues is less polar (or more hydrophobic) upon the interaction of NPG, and as a consequence, these residues are less exposed to the solvent or have been lost solvent (water lubrication) in your vicinity. In contrast, when $\Delta \lambda=15 \mathrm{~nm}$ (Fig. 5B), the synchronous fluorescence intensity of Tyr residues of this protein was accompanied with a decrease and red-shift $(\sim 4 \mathrm{~nm})$ in the emission maxima, and then, this spectral change can be due to a microenvironment more polar (or less hydrophobic) around of Tyr residues of OVA and the peptide strand unfolding. Furthermore, in the same figure, 5A and 5B also can see the behavior of ratios of synchronous fluorescence quenching Fs $\left(F s=F_{0} / F\right)$ with the concentration of NPG; in the present case, $F_{0}$ and $F$ are the synchronous 
fluorescence intensities of OVA in the absence and the presence of NPG, respectively. It is clear; the slope was higher when $\Delta \lambda=60 \mathrm{~nm}$ indicating a higher contribution of the Trp residues in the quenching of fluorescence of OVA. This result also suggests that the molecular forces that promote an environment more hydrophobic around Trp are dominant.

A piece of evidence additional about the conformational change induced in OVA that occurs by binding of NPG becomes from 3D fluorescence measurements [39]. In this technique, excitation wavelength, emission wavelength, and fluorescence intensity are used as axes in the fluorescence emission spectra, and the changes or perturbations observed in this three-dimensional fluorescence spectrum are related with changes in the conformation of the primary peptide structure and micro-polarity of amino acid residues [40,41]. In Fig. 6, can be seen that fluorescence spectral characteristics of Trp, Tyr, and polypeptide backbone are quenched due to the presence of NPG. Furthermore, the Rayleigh scattering peak is increased approximately two times in comparison with this same peak for OVA in the absence of NPG; as known, the Rayleigh intensity depends on the square of the molecular polarizability. Interestingly, we recently have shown that a change in electronic polarizability of protein induced by electronic interaction with small ligand affects the hydration degrade on the surface of the protein and molecular volume. And then, based on the relation between this electronic property and molecular volume [42], can be suggested that this increase in molecular polarizability or volume can be due to a change in the hydration and conformation in the spatial structure protein, which is in concordance with the observed in the synchronous fluorescence spectra (see Fig 5).

\subsection{Thermodynamic parameters.}

The study of the temperature dependence of the association of the NPG to OVA is very important because the thermodynamic parameters associated with this process give information about the forces involved in the mechanism of the binding of a ligand to proteins. The binding or association constant $\left(\mathrm{K}_{\mathrm{b}}\right)$ and the number of independent binding sites (n) were to estimate at each temperature following the equations (7-9) and linear regression analysis [34,43,44].

$$
\log \left(\frac{F-F_{0}}{F}\right)=n \log K_{b}+n \log [Q]_{n b}
$$

From the slope of a straight line of the plot of $\log \left(F-F_{0} / F\right)$ vs. $\log [Q]_{n b}$ was obtained the parameter, $\mathrm{n}$, and from of the intercept on $\mathrm{Y}$-axis was obtained the binding constant $\mathrm{K}_{\mathrm{b}}$. Where $[\mathrm{Q}]_{\mathrm{nb}}$ is the free quencher concentration in solution, which can be estimated from.

$$
\begin{aligned}
& {[Q]_{n b}=[Q]-m\left(\frac{F-F_{0}}{F}\right)} \\
& {[Q]=a+m\left(\frac{F}{F_{0}}\right)}
\end{aligned}
$$

In Table 2 are shown the values obtained for these parameters $\mathrm{K}_{\mathrm{b}}$ and $\mathrm{n}$. As can be seen, the number of independent binding sites and the constant binding exhibit a slight change with the temperature. The number of independent binding sites has a value of about 1.3; values similar were reported early, and was propose that interaction between ligand and protein occurs 
in a ratio of 1:1 $[14,35]$. These results confirm the interaction NPG with OVA protein and that an NPG molecule binds to OVA.

Table 2. Binding constant $(K b)$ and the number of independent binding sites $(n)$ in the OVA-NPG system.

\begin{tabular}{c|c|c|c}
$\mathrm{T}, \mathrm{K}$ & ${ }^{\mathrm{a}} \mathrm{K}_{\mathrm{b}} \times 10^{3}$ & $\mathrm{n}$ & $\mathrm{R}^{2}(\mathrm{COD})$ \\
\hline 293.15 & 0.96 & 1.3 & 0.9976 \\
\hline 298.15 & 1.01 & 1.3 & 0.9971 \\
\hline 303.15 & 1.07 & 1.3 & 0.9982 \\
\hline 308.15 & 1.18 & 1.4 & 0.9948
\end{tabular}

The thermodynamic information about this binding was obtained following the equations (10) and (11)

$$
\begin{aligned}
& \ln K=-\frac{\Delta H^{\circ}}{R T}+\frac{\Delta S^{\circ}}{R} \\
& \Delta G^{\circ}=\Delta H^{\circ}-T \Delta S^{\circ}
\end{aligned}
$$

As seen from the results given in Table $3, \Delta \mathrm{H}^{\circ}$ is positive (endothermic process), while $\Delta S^{\circ}$ is a positive quantity; both are constant in the range of temperature studied. As a consequence, $\Delta \mathrm{G}^{\circ}$ is negative too, but the value of this property mainly depends on the $\mathrm{T} \Delta \mathrm{S}^{\circ}$ term - the process is entropically controlled, and as expected for an entropic process, the magnitude of Gibbs free energy increases as increase the temperature (Table 3). It is very important to note that these results indicate that the formation of the OVA-NPG complex is a spontaneous process, which is consistent with a static quencher process. And thus, based on the study reported by Ross and Subramanian [45], when $\Delta \mathrm{H}^{\circ}>0$ and $\Delta \mathrm{S}^{\circ}>0$ are possible to suggest that the formation of the complex is governed mainly by hydrophobic forces. It is noteworthy that it has been shown that the pocket-ligand hydrophobic association is entropicdriven due to that the association causes dehydration, which is promoted by gain configurational-translational entropy of water molecules for the decrease in the excludedvolume upon association [46].

Table 3. Thermodynamic parameters Gibbs free energy $\left(\Delta \mathrm{G}^{\circ}\right)$, Enthalpy $\left(\Delta \mathrm{H}^{\circ}\right)$, and Entropy $\left(\Delta \mathrm{S}^{\circ}\right)$ for the

\begin{tabular}{|c|c|c|c|c|}
\hline $\mathrm{T}(\mathrm{K})$ & $\Delta \mathrm{H}^{\circ}(\mathrm{KJ} / \mathrm{mol})$ & $\begin{array}{c}\Delta \mathrm{S}^{\circ} \\
(\mathrm{J} / \mathrm{K} \mathrm{mol})\end{array}$ & $\Delta \mathrm{G}^{\circ}(\mathrm{KJ} / \mathrm{mol})$ & $\mathrm{R}^{2}(\mathrm{COD})$ \\
\hline 293.15 & \multirow{4}{*}{10.34} & \multirow{4}{*}{92.21} & -16.70 & \multirow{4}{*}{0.9644} \\
\hline 298.15 & & & -17.16 & \\
\hline 303.15 & & & -17.62 & \\
\hline 308.15 & & & -18.08 & \\
\hline
\end{tabular}
interaction in the OVA-NPG system.

\subsection{Laser doppler velocimetry measurements.}

More evidence about the formation of the complex OVA-NPG was obtained from measures of Zeta potential. In the Fig. 7, is shown the zeta potential changes of OVA in the water at $298.15 \mathrm{~K}$ induced by the addition of the compound NPG. As can to see, the interaction of NPG with OVA produced a decrease in the positive charge on the protein. And thus, the zeta potential of OVA in pure water is - $43 \mathrm{mV}$; this value has excellent concordance with the value reported previously under similar conditions [47]. As the NPG concentration increases, this negative charge in the double layer strongly reduces due to the decreasing of the thickness of the electrical double layer by the accumulation of NPG molecules on the surface of the protein. This diminution has a linear behavior with the concentration of NPG. This result suggests both 
the existence of strong electrostatic interactions between the protein and NPG molecules and the respective formation of the OVA-NPG complex. Similar behavior has been reported for electrostatic interaction between HSA protein and ionic drugs [47]. These results show that the binding of NPG to OVA is a complex process that has an interplay between hydrophobic forces and neutralization of electrostatic charge.

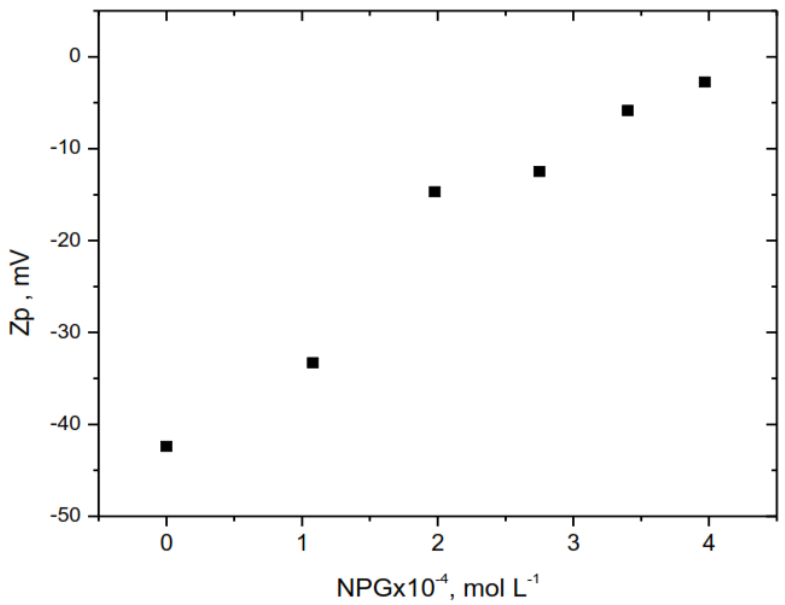

Figure 7. Zeta potential changes of OVA in the water at $298.15 \mathrm{~K}$ in the presence of NPG.

\subsection{Volumetric results.}

The formation of complexes and conformational transitions in protein by binding of the small or big ligand is known to induce changes in the partial molar volume of protein [29]. However, it is very important to mention that these changes in volume molar of protein, $\Delta \mathrm{V}_{2}$, in general, do not exceed in magnitude to $10 \%$ of the value of the partial molar volume of protein at infinite dilution $\mathrm{V}_{2}{ }^{\infty}$ and theoretically for a protein of molecular weight of $50 \mathrm{kDa}$ very close to OVA ( $45 \mathrm{kDa})$, the change in the molar volume is approximately equal to $225 \mathrm{~cm}^{3} / \mathrm{mol}$ for a modest $20 \%$ unfolding [29]. Also, recently was reported that the binding of C3G (cyanidyn-3-O-glucoside) to OVA-induced a slightly increased in the diameter of protein[48].

With this evidence in mind, we carried out in this work the determination of $\mathrm{V}_{2}{ }^{\infty}$ of OVA in the absence and presence of NPG at $298.15 \mathrm{~K}$, and the results obtained using the Redlich's equation of two terms were $35138.20 \pm 47.44 \mathrm{~cm}^{3} / \mathrm{mol}^{-1}$ and $35201.16 \pm 67.49$ $\mathrm{cm}^{3} / \mathrm{mol}^{-1}$, respectively (see Table $\mathrm{S} 1$ in supplementary material). This result revealed that the interaction between OVA and NPG compound is accompanied by a very modest increase in the limiting partial molar volume. In fact, the value estimated for the transfer volume of OVA from water to aqueous-NPG solution is only $62.96 \pm 19 \mathrm{~cm}^{3} / \mathrm{mol}^{-1}$. Interestingly, Chalikian et $a l$. have reported that the interaction of tri-N-acetylglucosamine $(0.5 \mathrm{M})$ to OVA at $298.15 \mathrm{~K}$ occurs with an increase in the volume of $50 \mathrm{~cm}^{3} / \mathrm{mol}$ and without undergoing any change in the spatial configuration of this protein. These authors argued a binding reaction with a loss of 4 water molecules [30]. In this study from acoustic measurements (see Table S2 in supplementary material) and Pasynski's method, we have found that this binding occurs with the loss of 20 water molecules $\left(\Delta n_{h}=-20\right)$. This loss of water involves possibly both water on the surface of protein as of their interior (water of lubrication in the interior of the cavity). This result is in concordance with the observed by us about Trp using synchronous fluorescence spectroscopy. And then, these volumetric and acoustic results permit suggest that the binding of NPG to OVA, induced a change in the hydration of some sites of state native of OVA, which 
promote a configuration transition from native state to a partially unfolding state, with an unfolding very likely well below at $20 \%$ as expected from $\Delta \mathrm{V}_{2}$ [29].

\subsection{Molecular modeling and molecular dynamics simulations.}

All the docking algorithms used predicted that the NPG ligand is capable of interacting thermodynamically in a favorable way with two cavities, one internal and one external or surface in Ovalbumin (PDB: 1OVA). In the case of the internal cavity, the docking energies were $-4.70 \mathrm{Kcal} / \mathrm{mol}^{-1},-6.280 \mathrm{Kcal} / \mathrm{mol}^{-1},-72.187 \mathrm{Kcal} / \mathrm{mol}^{-1},-62.016 \mathrm{Kcal} / \mathrm{mol}^{-1}$, and -45.780 $\mathrm{Kcal} / \mathrm{mol}^{-1}$ for the scoring functions AutoDock Vina (from COACH-D server), DockT Score (from DockThor server), MolDock Score, Rerank Score, and PLANTS Score (all from Molegro package), respectively. Additionally, hydrophobic interactions with NPG predominated in the predicted internal cavity. Specifically, the NPG ligand established hydrogen bonds with Asn101(D) and Thr104(D), and steric/hydrophobic interactions with residues Asn101(C), Lys105(C), Pro106(C), Leu100(D), Asn101(D), Gln102(D), Lys105(D) and Pro106(D). The residues involved in these interactions contribute locally to a total hydrophobicity ratio of $14 \%$, resulting in a local hydropathy of -1,980 to the binding pocket indicative of a hydrophilic region. Thus, we found that the NPG ligand was docking at a mean distance between 7 to $14 \AA$ from the closest pair of Tyr-Trp residues (see Table 4).

While the surface cavity presented energies of $-3.30 \mathrm{kcal} / \mathrm{mol}^{-1},-5.846 \mathrm{kcal} / \mathrm{mol}^{-1}$, $72.230 \mathrm{kcal} / \mathrm{mol}^{-1},-60.742 \mathrm{kcal} / \mathrm{mol}^{-1}$, and $-46.473 \mathrm{kcal} / \mathrm{mol}^{-1}$ according to AutoDock Vina, DockT Score, MolDock Score, Rerank Score, and PLANTS Score, respectively (see Table 4). In this external cavity (see Fig.8), hydrophobic interactions were notoriously more predominant locally than those predicted in the internal cavity, establishing hydrogen bridges with Lys367(A) and Lys377(A), and steric interactions with 2 Lys, 2 Asn, 2 Ala, 2 Phe, 2 Met, 2 Ile, $4 \mathrm{Thr}, 4 \mathrm{Leu}$, and $5 \mathrm{Ser}$. All of these residues are located in the A chain of the 1OVA, and at a distance of approximately 7-14 $\AA$ from the closest pair of Tyr-Trp residues. With a total hydrophobicity ratio of the residues involved in the docking of approximately $48 \%$ and contributing locally to a hydropathy of 0.624 , a characteristic score of a sparingly soluble region within the junction pocket.

These results show that, although the internal cavity has coupling energies favored by $3 / 5$ of the scoring functions considered, the external cavity has hydrophobic characteristics suitable for better coupling of this type of ligand. An observation that corresponds to the experimental results obtained in this study and that is favorable for this type of ligand that meets all the Lipinski criteria as determined with the SwissADME web server tools. Furthermore, it is important to point out that the COACH-D server was first used here for a molecular coupling study of compounds targeting 1OVA. It is noteworthy that this protein binds curcumin in a similar way where the hydrophobicity and specific ( $\mathrm{H}$ bonding) interactions are the dominant forces [14]. Thus, a platform that represents an improvement over its previous version, and that performs a thorough sampling and accurate prediction of the binding site based on the integration of five individual methods (TM-SITE, S-SITE, COFACTOR, FINDSITE, and ConCavity) to forecast consensus of pockets and binding residues for the ligand-protein complex [49]. This thus increases the probability of hits and reproducibility of the results of this study in relation to the most probable cavity for docking. Interestingly, the methods used here too predicted that hydrophobic compounds such as methylene blue and warfarin bind this same superficial cavity, which previously were reported with thermodynamically favored coupling to Ovalbumin using other methods [50]. 
These results are interesting because they show that other algorithms, even those associated with the MolDock scoring function (which in this study predicted a more favorable coupling in the external cavity) reproduce scores such as those predicted by Glide, which is a very precise algorithm, which has recently been used in OVA related coupling studies [50,51] which is important considering that MolDock is even more accurate than Glide in predicting the binding site [52]. Once again, validating the reproducibility of the results of this research, which derive from the prediction of a very precise docking supported by six sampling algorithms. In this sense, we consider that the binding in the external cavity of OVA is in concordance with the experimental results that suggest that hydrophobicity is the force predominant in the comparison to hydrogen bonding and charge neutralization in this system. Then, the OVA-NPG complex obtained from the docking between the ligand and the external cavity of the 1OVA was chosen for the following molecular dynamics analyzes.

Regarding the analysis of molecular dynamics, specifically in terms of the alteration of the total energy of the thermodynamically favorable complex predicted between the ligand and the external cavity, it could be observed that the ligand was capable of inducing disturbances in the thermodynamic stability of the protein. This interaction caused the complex to reach a minimum energy structure at $50 \mathrm{~ns}$, keeping the perturbations stable in this range throughout the simulation. In fact, in less time, the OVA-NPG complex reaches low energy than the protein OVA in the native state (see Figure 9). These results correspond to the structural disturbances measured from the pair of Glu225 (D) and His362 (D) residues used as a reference and chosen arbitrarily because they are located close to the ligand. Distances were determined after four complete simulation cycles at $100 \mathrm{~ns}$ each, and between the alpha carbon atoms of each residue. It was observed that the state of highest refolding was reached around 50 - 60 ns with a difference with respect to the most deployed initial state of approximately $10 \%$. However, this state remained relatively stable during the rest of the simulation. Because the protein shows a structural fluctuation with the time around this initial configuration, which is indicative of a thermodynamic and structural stabilization of 1OVA induced by binding with the NPG ligand in the surface cavity, which produces an unfolded state in relation to the protein native, they are determining that under the conditions of this study, there is a good correlation between the structural disturbance and the thermodynamic stability of the ligand-protein complex ( $\mathrm{Rp} \geq$ 0.80) (see Table 4 and Figure 9A, 9B). In contrast, the OVA protein in their native state reaches by refolding in the time a minimum energy configuration more compact in comparison to their initial native state and the OVA-NPG complex.

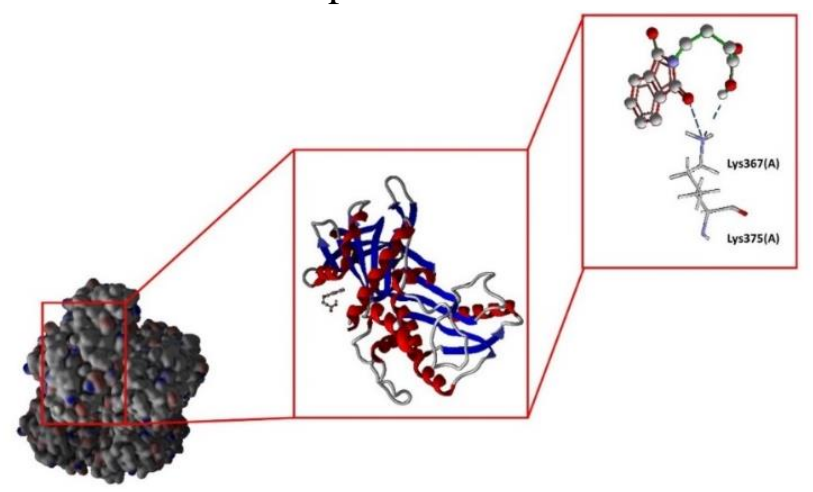

Figure 8. Visualization of the result of 1OVA-NPG docking. The results of the coupling of the compound on the external cavity with the best interaction energy show. Hydrogen bond interaction with Lys367 and Lys375 also is shown in this same figure. 


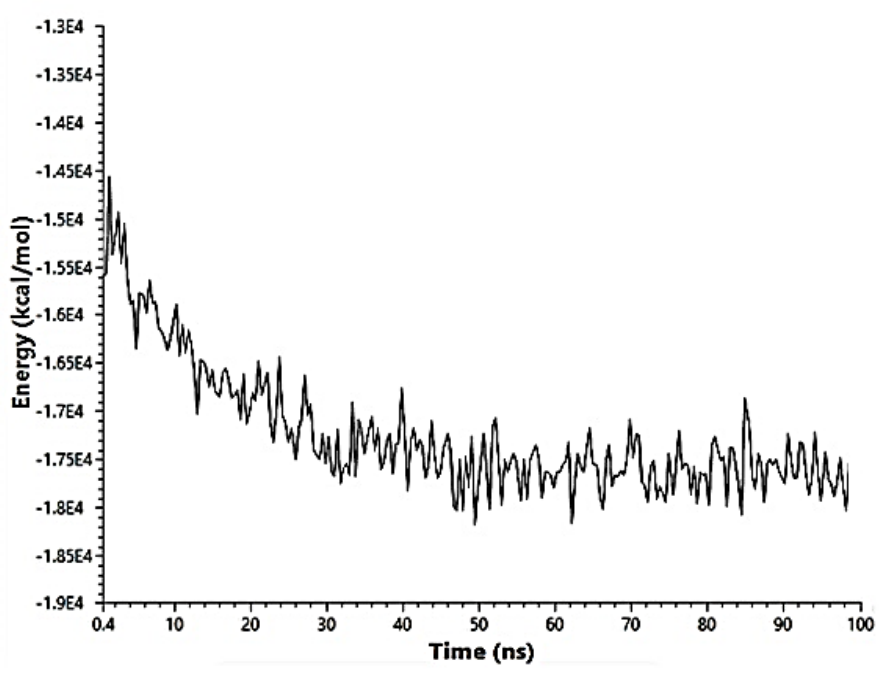

A

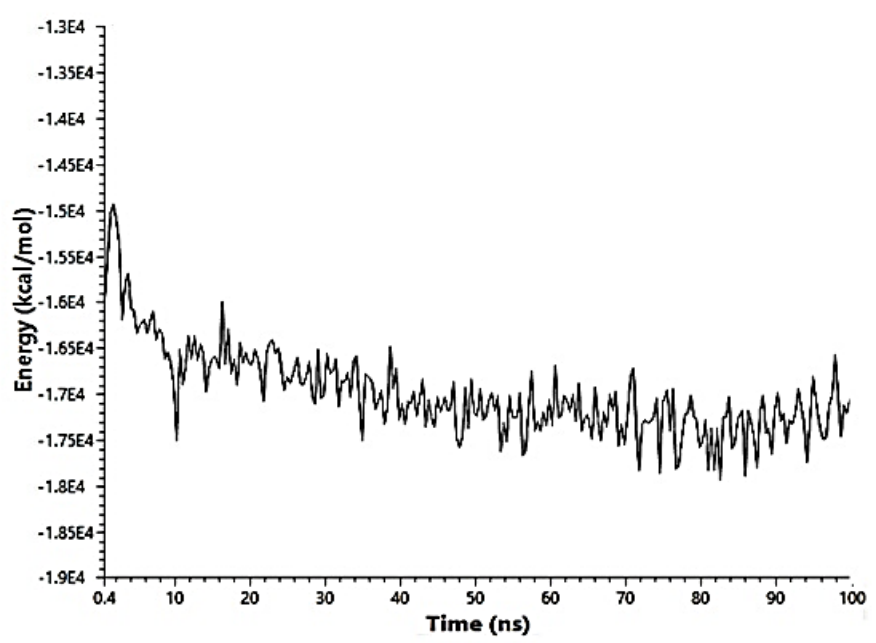

B

Figure 9. The fluctuation of the thermodynamic stability of Ovalbumin (1OVA) with (A) and without (B) the NPG ligand at $100 \mathrm{~ns}$.

Table 4. Virtual docking for N-Phthaloyl gamma-aminobutyric acid derivative (NPG) and Ovoalbumin (Ova)

\begin{tabular}{|c|c|c|c|c|c|c|}
\hline \multirow{2}{*}{$\begin{array}{c}\text { Ova } \\
+ \\
\text { NPG }\end{array}$} & \multicolumn{5}{|c|}{$\begin{array}{l}\text { Molecular Docking } \\
(\mathrm{kcal} / \mathrm{mol})\end{array}$} & \multirow[b]{2}{*}{ Interaction $^{\mathrm{b}}$} \\
\hline & $\begin{array}{l}\text { ADV } \\
\text { Score }^{a}\end{array}$ & $\begin{array}{l}\text { DockT } \\
\text { Score }\end{array}$ & $\begin{array}{l}\text { MolDock } \\
\text { Score }\end{array}$ & $\begin{array}{l}\text { Rerank } \\
\text { Score }\end{array}$ & $\begin{array}{l}\text { Plants } \\
\text { Score }\end{array}$ & \\
\hline $\begin{array}{l}\text { External } \\
\text { cavity }\end{array}$ & -3.30 & -5.846 & -72.230 & -60.742 & -46.473 & 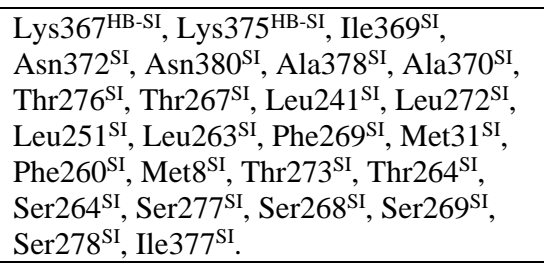 \\
\hline $\begin{array}{l}\text { Internal } \\
\text { cavity }\end{array}$ & -4.70 & -6.280 & -72.187 & -62.016 & -45.780 & 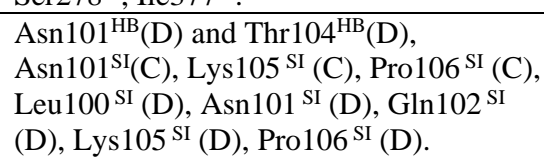 \\
\hline
\end{tabular}

a, AutoDock Vina Score from the COACH-D server; DockT Score, a scoring function of DockThor software; MolDock, Rerank and PLANTS Score, scoring functions present in Molegro Molecular; HB, hydrogen bond; SI, steric interactions; ${ }^{\text {b }}$ The residues involved in these interactions belong to the A chain and contribute locally with a total hydrophobicity ratio of approximately $48 \%$ resulting in a local hydropathy of -0.624 in the junction pocket. The mean distance of the analog to Tyr-Trp was approximately 7-14 A. 


\section{Conclusions}

In this work was studied the interaction between the OVA protein and NPG compound using fluorescence spectroscopy, laser Doppler velocimetry, acoustic densimetry, molecular docking theoretical and molecular dynamics theoretical simulations. The results have shown that NPG compound is a quencher of the intrinsic fluorescence of OVA by a static quenching mechanism and that the NPG compound bind to the surface cavity of OVA protein following a mechanism mediated by hydrophobicity forces, hydrogen bonds, and neutralization of electric charge of superficial amino acid residues to protein. Hydrophobic forces are having the greatest contributions within this mechanism. This binding reaction is a spontaneous thermodynamic process, which is under entropic control, and this binding causes a conformational change in the protein. The results here obtained are in excellent agreement with the recent study reported by Ximenes and co-workers[53] in: A) the binding of a ligand under entropic control due to gain in the translational degrees of freedom of solvent when it is removed from the hydration layer of the hydrophobic solute as to as of the cavity of protein when occurs the binding which exceeds the entropy loss expected in a typical guest/host interaction, and B) the observed increase in the Stern-Volmer KSV and quenching Kq constant as increase the temperature, in this case, is associated with a static mechanism dominate by hydrophobic forces (entropic control) and not with a dynamic mechanism as expected by the universally accepted criterion in the literature. This study gives useful information about the interaction between transport proteins, and gabapentin and thalidomide derivatives, due to that NPG compound contain fragments of both drugs.

\section{Funding}

This research was funded by Fondo Nacional de Ciencia, Tecnología e Innovación (FONACIT, Misión Ciencia) grant number 2007000881.

\section{Acknowledgments}

The authors thank the financial support to Fondo Nacional de Ciencia, Tecnología e Innovación (FONACIT, Misión Ciencia), and, Venezuelan Institute of Scientific Research and the convenio inter-institucional IVIC-LUZ.

\section{Conflicts of Interest}

The authors declare no conflict of interest.

\section{References}

1. Aziz, H.A.; Tan, Y.T.F.; Peh, K.K. Solubility of Drugs in Aqueous Polymeric Solution: Effect of Ovalbumin on Microencapsulation Process. AAPS PharmSciTech 2012, 13, 35-45, https://doi.org/10.1208/s12249-0119707-x.

2. Ghosh, D.; Chattopadhyay, N. Equilibrium and Dynamic Effects on Ligand Binding to Biomacromolecules and Biomimetic Model Systems. Int. Rev. Phys. Chem. 2013, 32, 435-466, https://doi.org/10.1080/0144235X.2013.782683.

3. Lu, Y.; Wang, Y.L.; Gao, S.H.; Wang, G.K.; Yan, C.L.; Chen, D.J. Interaction of Quercetin with Ovalbumin: Spectroscopic and Molecular Modeling Studies. J. Lumin. 2009, 129, 1048-1054, https://doi.org/10.1016/j.jlumin.2009.04.030.

4. Monkos, K. Viscosity Analysis of the Temperature Dependence of the Solution Conformation of Ovalbumin. Biophys. Chem. 2000, 85, 7-16, https://doi.org/10.1016/S0301-4622(00)00127-7.

5. Rajaian, H.; Symonds, H.W.; Bowmer, C.J. Drug Binding Sites on Chicken Albumin: A Comparison to 
Human Albumin. J. Vet. Pharmacol. Ther. 1997, 20, 421-426, https://doi.org/10.1046/j.13652885.1997.00099.X

6. Li, X.; Yan, Y. Comparative Study of the Interactions between Ovalbumin and Five Antioxidants by Spectroscopic Methods. J. Fluoresc. 2017, 27, 213-225, https://doi.org/10.1007/s10895-016-1948-3.

7. Rao, S.; Xu, G.; Lu, X.; Zhang, R.; Gao, L.; Wang, Q.; Yang, Z.; Jiao, X. Characterization of OvalbuminCarvacrol Inclusion Complexes as Delivery Systems with Antibacterial Application. Food Hydrocoll. 2020, 105, https://doi.org/10.1016/j.foodhyd.2020.105753.

8. Frokjaer, S.; Otzen, D.E. Protein Drug Stability: A Formulation Challenge. Nat. Rev. Drug Discov. 2005, 4, 298-306, https://doi.org/10.1038/nrd1695.

9. Kamerzell, T.J.; Esfandiary, R.; Joshi, S.B.; Middaugh, C.R.; Volkin, D.B. Protein-Excipient Interactions: Mechanisms and Biophysical Characterization Applied to Protein Formulation Development. Adv. Drug Deliv. Rev. 2011, 63, 1118-1159, https://doi.org/10.1016/j.addr.2011.07.006.

10. Rajamanikandan, R.; Selva Sharma, A.; Ilanchelian, M. New Insights into the Binding Interaction of Food Protein Ovalbumin with Malachite Green Dye by Hybrid Spectroscopic and Molecular Docking Analysis. J. Biomol. Struct. Dyn. 2019, 37, 4292-4300, https://doi.org/10.1080/07391102.2018.1550441.

11. Ma, Z.; Prasanna, G.; Jiang, L.; Jing, P. Molecular Interaction of Cyanidin-3-O-Glucoside with Ovalbumin: Insights from Spectroscopic, Molecular Docking and in Vitro Digestive Studies. J. Biomol. Struct. Dyn. 2020, 38, 1858-1867, https://doi.org/10.1080/07391102.2019.1618735.

12. de Lyra, A.C.F.; dos Santos Silva, A.L.; dos Santos, E.C.L.; López, A.M.Q.; da Silva, J.C.S.; Figueiredo, I.M.; Santos, J.C.C. Molecular Interaction of Sulfonamides and Ovalbumin, an Allergenic Egg Protein, Exploring Biophysical, Theoretical and Biological Studies. Spectrochim. Acta - Part A Mol. Biomol. Spectrosc. 2020, 228, https://doi.org/10.1016/j.saa.2019.117747.

13. Dantas, M.D.D.A.; Tenório, H.D.A.; Lopes, T.I.B.; Pereira, H.J.V.; Marsaioli, A.J.; Figueiredo, I.M.; Santos, J.C.C. Interactions of Tetracyclines with Ovalbumin, the Main Allergen Protein from Egg White: Spectroscopic and Electrophoretic Studies. Int. J. Biol. Macromol. 2017, 102, 505-514, https://doi.org/10.1016/j.ijbiomac.2017.04.052.

14. Liu, Y.; Cai, Y.; Ying, D.; Fu, Y.; Xiong, Y.; Le, X. Ovalbumin as a Carrier to Significantly Enhance the Aqueous Solubility and Photostability of Curcumin: Interaction and Binding Mechanism Study. Int. J. Biol. Macromol. 2018, 116, 893-900, https://doi.org/10.1016/j.ijbiomac.2018.05.089.

15. Sen, S.; Habibuddin, M.; Pal, S.P. Antiulcer and Gastric Secretory Activity of N-Octanoyl $\gamma$ - Aminobutyric Acid. Life Sci. 1995, 57, 1877-1885, https://doi.org/10.1016/0024-3205(95)02168-I.

16. Subramanian, P.; Subash, S. Effect of N-Phthaloyl Gamma-Aminobutyric Acid on Lipid Peroxidation, Antioxidants and Liver Markers in Constant Light Exposed Rats. Int. J. Nutr. Pharmacol. Neurol. Dis. 2011, 1, 163-166, https://doi.org/10.4103/2231-0738.84208.

17. Pace, C.N.; Felix, V.; Lanette, F.; Gerald, G.; Theronica, G. Applications de La Micro Extraction En Phase Solide ( SPME ) Pour La Maîtrise de La Qualité et de La Sécurité Des Vins. Prorein Sci. 1995, 4, 24112423.

18. Zeyad Yasseena, B.Z. Binding and Thermodynamic Parameters of Ovalbumin-Oleic Acid Conjugate. IUG J. Nat. Stud. 2018, 16.

19. Ghosh, K.S.; Sen, S.; Sahoo, B.K.; Dasgupta, S. A Spectroscopic Investigation into the Interactions of 3'-OCarboxy Esters of Thymidine with Bovine Serum Albumin. Biopolymers 2009, 91, 737-744, https://doi.org/10.1002/bip.21220.

20. Lakowicz, J.R. Principles of Fluorescence Spectroscopy. 2006; https://doi.org/10.1007/978-0-387-46312-4.

21. Alvarado, Y.J.; Cubillán, N.; Chacín-Molero, E.; Ferrer-Amado, G.; Hernández-Labarca, P.; Velazco, W.; Ojeda-Andara, J.; Marrero-Ponce, Y.; Arrieta, F. Experimental and Theoretical Determination of the Limiting Partial Molar Volume of Indole in CCl4, Tetrahydrofuran and Acetonitrile at $293.15 \mathrm{k}$ : A Comparative Study with Benzimidazole and Benzothiophene. J. Solution Chem. 2010, 39, 277-290, https://doi.org/10.1007/s10953-010-9511-3.

22. Alvarado, Y.J.; Caldera-Luzardo, J.; Ferrer-Amado, G.; Mancilla-Labarca, V.; Michelena, E. Determination of the Apparent Molar Refraction and Partial Molar Volume at Infinite Dilution of Thiophene-, Pyrrole- and Furan-2-Carboxaldehyde Phenylhydrazone Derivatives in Acetonitrile at 293.15 K. J. Solution Chem. 2007, 36, 1-11, https://doi.org/10.1007/s10953-006-9093-2.

23. Shek, Y.L.; Chalikian, T.V. Interactions of Glycine Betaine with Proteins: Insights from Volume and Compressibility Measurements. Biochemistry 2013, 52, 672-680, https://doi.org/10.1021/bi301554h.

24. Santosh, M.S.; Krishna Bhat, D.; Bhatt, A.S. Ultrasonic Velocities, Densities, and Viscosities of Glycylglycine and $\mathrm{CoCl} 2$ in Aqueous and Aqueous Ethanol Systems at Different Temperatures. J. Chem. Thermodyn. 2010, 42, 742-751, https://doi.org/10.1016/j.jct.2010.01.010.

25. Ajmal, M.R.; Nusrat, S.; Alam, P.; Zaidi, N.; Khan, M.V.; Zaman, M.; Shahein, Y.E.; Mahmoud, M.H.; Badr, G.; Khan, R.H. Interaction of Anticancer Drug Clofarabine with Human Serum Albumin and Human a-1 Acid Glycoprotein. Spectroscopic and Molecular Docking Approach. J. Pharm. Biomed. Anal. 2017, 135, 106-115, https://doi.org/10.1016/j.jpba.2016.12.001.

26. Delahaije, R.J.B.M.; Wierenga, P.A.; Van Nieuwenhuijzen, N.H.; Giuseppin, M.L.F.; Gruppen, H. Protein Concentration and Protein-Exposed Hydrophobicity as Dominant Parameters Determining the Flocculation 
of Protein-Stabilized Oil-in-Water Emulsions. Langmuir 2013, 29, 11567-11574. https://doi.org/10.1021/la401314a.

27. Khan, R.S.; Rehman, I. Spectroscopy as a Tool for Detection and Monitoring of Corona Virus (COVID-19). Expert Rev. Mol. Diagn. 2020, 0, 647-649, https://doi.org/10.1080/14737159.2020.1766968.

28. Kasahara, K.; Benson Ma, K.G.; Bhaskar, D.; Junichi, H.; Ikuo, F.; Tadaaki, M.; Yutaka, A.; Nakamura, H. MyPresto/Omegagene: A GPU-Accelerated Molecular Dynamics Simulator Tailored for Enhanced Conformational Sampling Methods with a Non-Ewald Electrostatic Scheme. Biophys. Physicobiology 2016, 13, 209-216, https://doi.org/10.2142/biophysico.13.0.

29. Chalikian, T.V.; Filfil, R. How Large Are the Volume Changes Accompanying Protein Transitions and Binding? Biophys. Chem. 2003, 104, 489-499, https://doi.org/10.1016/S0301-4622(03)00037-1.

30. Son, I.; Shek, Y.L.; Dubins, D.N.; Chalikian, T.V. Volumetric Characterization of Tri-N-Acetylglucosamine Binding to Lysozyme. Biochemistry 2012, 51, 5784-5790, https://doi.org/10.1021/bi3006994.

31. Abou-Zied, O.K.; Al-Lawatia, N. Exploring the Drug-Binding Site Sudlow i of Human Serum Albumin: The Role of Water and Trp214 in Molecular Recognition and Ligand Binding. ChemPhysChem 2011, 12, 270274, https://doi.org/10.1002/cphc.201000742.

32. Zhang, W.; Xiong, X.; Wang, F.; Ge, Y.; Liu, Y. Studies of the Interaction between Ronidazole and Human Serum Albumin by Spectroscopic and Molecular Docking Methods. J. Solution Chem. 2013, 42, 1194-1206, https://doi.org/10.1007/s10953-013-0027-5.

33. Sarkar, M.; Paul, S.S.; Mukherjea, K.K. Interaction of Bovine Serum Albumin with a Psychotropic Drug Alprazolam: Physicochemical, Photophysical and Molecular Docking Studies. J. Lumin. 2013, 142, 220230, https://doi.org/10.1016/j.jlumin.2013.03.026.

34. Bi, S.; Song, D.; Kan, Y.; Xu, D.; Tian, Y.; Zhou, X.; Zhang, H. Spectroscopic Characterization of Effective Components Anthraquinones in Chinese Medicinal Herbs Binding with Serum Albumins. Spectrochim. Acta - Part A Mol. Biomol. Spectrosc. 2005, 62, 203-212, https://doi.org/10.1016/j.saa.2004.12.049.

35. Roufegarinejad, L.; Amarowicz, R.; Jahanban-Esfahlan, A. Characterizing the Interaction between Pyrogallol and Human Serum Albumin by Spectroscopic and Molecular Docking Methods. J. Biomol. Struct. Dyn. 2019, 37, 2766-2775, https://doi.org/10.1080/07391102.2018.1496854.

36. Pacheco, M.E.; Bruzzone, L. Synchronous Fluorescence Spectrometry: Conformational Investigation or Inner Filter Effect? J. Lumin. 2013, 137, 138-142, https://doi.org/10.1016/j.jlumin.2012.12.056.

37. Cheng, Z.; Liu, R.; Jiang, X. Spectroscopic Studies on the Interaction between Tetrandrine and Two Serum Albumins by Chemometrics Methods. Spectrochim. Acta - Part A Mol. Biomol. Spectrosc. 2013, 115, 92105, https://doi.org/10.1016/j.saa.2013.06.007.

38. Mi, R.; Hu, Y.J.; Fan, X.Y.; Ouyang, Y.; Bai, A.M. Exploring the Site-Selective Binding of Jatrorrhizine to Human Serum Albumin: Spectroscopic and Molecular Modeling Approaches. Spectrochim. Acta - Part A Mol. Biomol. Spectrosc. 2014, 117, 163-169, https://doi.org/10.1016/j.saa.2013.08.013.

39. Tian, F.F.; Jiang, F.L.; Han, X.L.; Xiang, C.; Ge, Y.S.; Li, J.H.; Zhang, Y.; Li, R.; Ding, X.L.; Liu, Y. Synthesis of a Novel Hydrazone Derivative and Biophysical Studies of Its Interactions with Bovine Serum Albumin by Spectroscopic, Electrochemical, and Molecular Docking Methods. J. Phys. Chem. B 2010, 114, 14842-14853, https://doi.org/10.1021/jp105766n.

40. Punith, R.; Seetharamappa, J. Spectral Characterization of the Binding and Conformational Changes of Serum Albumins upon Interaction with an Anticancer Drug, Anastrozole. Spectrochim. Acta - Part A Mol. Biomol. Spectrosc. 2012, 92, 37-41, https://doi.org/10.1016/j.saa.2012.02.038.

41. Mahaki, H.; Memarpoor-Yazdi, M.; Chamani, J.; Reza Saberi, M. Interaction between Ropinirole Hydrochloride and Aspirin with Human Serum Albumin as Binary and Ternary Systems by MultiSpectroscopic, Molecular Modeling and Zeta Potential. J. Lumin. 2013, 134, 758-771, https://doi.org/10.1016/j.jlumin.2012.06.051.

42. Alvarado, Y.J.; Ferrebuz, A.; Paz, J.L.; Rodríguez-Lugo, P.; Restrepo, J.; Romero, F.; Fernández-Acuña, J.; Williams, Y.O.N.; Toro-Mendoza, J. Surface Behavior of BSA/Water/Carbohydrate Systems from Molecular Polarizability Measurements. J. Phys. Chem. B 2018, 122, 4231-4238, https://doi.org/10.1021/acs.jpcb.7b11998.

43. Shen, L.; Xu, H.; Huang, F.; Li, Y.; Xiao, H.; Yang, Z.; Hu, Z.; He, Z.; Zeng, Z.; Li, Y. Investigation on Interaction between Ligupurpuroside A and Pepsin by Spectroscopic and Docking Methods. Spectrochim. Acta - Part A Mol. Biomol. Spectrosc. 2015, 135, 256-263, https://doi.org/10.1016/j.saa.2014.06.087.

44. Wei, X.L.; Xiao, J.B.; Wang, Y.; Bai, Y. Which Model Based on Fluorescence Quenching Is Suitable to Study the Interaction between Trans-Resveratrol and BSA? Spectrochim. Acta - Part A Mol. Biomol. Spectrosc. 2010, 75, 299-304, https://doi.org/10.1016/j.saa.2009.10.027.

45. Ross, P.D.; Subramanian, S. Thermodynamics of Protein Association Reactions: Forces Contributing to Stability. Biochemistry 1981,20,3096-3102, https://doi.org/10.1021/bi00514a017.

46. Graziano, G. Molecular Driving Forces of the Pocket-Ligand Hydrophobic Association. Chem. Phys. Lett. 2012, 533, 95-99, https://doi.org/10.1016/j.cplett.2012.03.020.

47. Cheema, M. A.; Taboada, P.; Barbosa, S.; Juárez, J.; Gutiérrez-Pichel, M.; Siddiq, M.; Mosquera, V. Human Serum Albumin Unfolding Pathway upon Drug Binding: A Thermodynamic and Spectroscopic Description. J. Chem. Thermodyn. 2009, 41, 439-447, https://doi.org/10.1016/j.jct.2008.11.011. 
48. Fu, X.; Belwal, T.; He, Y.; Xu, Y.; Li, L.; Luo, Z. Interaction and Binding Mechanism of Cyanidin-3-OGlucoside to Ovalbumin in Varying PH Conditions: A Spectroscopic and Molecular Docking Study. Food Chem. 2020, 320, https://doi.org/10.1016/j.foodchem.2020.126616.

49. Wu, Q.; Peng, Z.; Zhang, Y.; Yang, J. COACH-D: Improved Protein-Ligand Binding Sites Prediction with Refined Ligand-Binding Poses through Molecular Docking. Nucleic Acids Res. 2018, 46, W438-W442, https://doi.org/10.1093/nar/gky439.

50. Manivel, P.; Parthiban, M.; Ilanchelian, M. Exploring the Binding Mechanism between Methylene Blue and Ovalbumin Using Spectroscopic Analyses and Computational Simulations. J. Biomol. Struct. Dyn. 2020, 38, 1838-1847, https://doi.org/10.1080/07391102.2019.1618734.

51. Aamir Qureshi, M.; Javed, S. Structural Dynamics Studies on the Binding of Aflatoxin B1 to Chicken Egg Albumin Using Spectroscopic Techniques and Molecular Docking. J. Biomol. Struct. Dyn. 2019, 1102, 3144-3155, https://doi.org/10.1080/07391102.2019.1652690.

52. Thomsen, R.; Christensen, M.H. MolDock: A New Technique for High-Accuracy Molecular Docking. Phys. Lett. Sect. B Nucl. Elem. Part. High-Energy Phys. 2008, 663, 1-6, https://doi.org/10.1021/jm051197e.

53. de Carvalho Bertozo, L.; Fernandes, A.J.F.C.; Yoguim, M.I.; Bolean, M.; Ciancaglini, P.; Ximenes, V.F. Entropy-Driven Binding of Octyl Gallate in Albumin: Failure in the Application of Temperature Effect to Distinguish Dynamic and Static Fluorescence Quenching. J. Mol. Recognit. 2020, 33, 1-12, https://doi.org/10.1002/jmr.2840. 


\section{Supplementary Material}

Table S1. Volumetric and Densitometric parameters for OVA-NPG mixtures.

\begin{tabular}{|c|c|c|c|}
\hline $\mathrm{C}_{2} \times 10^{-4}, \mathrm{~mol} . \mathrm{L}^{-1}$ & ${ }^{*} \rho, \mathrm{g} \cdot \mathrm{cm}^{-3}$ & \multicolumn{2}{|c|}{$* \mathrm{~V}_{2, \phi}, \mathrm{cm}^{3} \cdot \mathrm{mol}^{-1}$} \\
\hline \multicolumn{4}{|c|}{ OVA + Water } \\
\hline 0 & 0.997069 & & \\
\hline 0.20 & 0.997281 & 34318.31 & \\
\hline 0.70 & 0.997731 & 35460.15 & \\
\hline 1.20 & 0.998205 & 35444.87 & \\
\hline 1.50 & 0.998525 & 35188.14 & \\
\hline 2.30 & 0.999397 & 34769.60 & \\
\hline 2.99 & 0.999986 & 35174.10 & \\
\hline 3.49 & 1.000544 & 34969.03 & \\
\hline 3.99 & 1.001097 & 34825.26 & \\
\hline 5.99 & 1.003021 & 34975.19 & \\
\hline 7.98 & 1.004939 & 35058.68 & \\
\hline 9.98 & 1.007034 & 34928.06 & \\
\hline & ${ }^{a} \mathrm{~V}_{2}{ }^{\oplus}, \mathrm{cm}^{3} \cdot \mathrm{mol}^{-1}$ & 35010.13 & () 321.36 \\
\hline & ${ }^{b} \mathrm{~V}_{2^{\oplus}}, \mathrm{cm}^{3} \cdot \mathrm{mol}^{-1}$ & 35138.20 & \pm 47.44 \\
\hline & (ㅇ), g.mol-1 & 9.9648 & \pm 0.0472 \\
\hline \multicolumn{4}{|c|}{$O V A+N P G$} \\
\hline 0 & 0.997152 & & \\
\hline 2.06 & 0.999177 & 3526712 & \\
\hline 2.58 & 0.999661 & 35357.02 & \\
\hline 3.44 & 1.000520 & 35308.50 & \\
\hline 5.15 & 1.002191 & 35314.83 & \\
\hline 6.18 & 1.003186 & 35336.36 & \\
\hline 7.21 & 1.004189 & 35340.61 & \\
\hline 8.24 & 1.005319 & 35188.42 & \\
\hline 9.27 & 1.006203 & 35336.18 & \\
\hline \multirow[t]{4}{*}{10.30} & 1.007387 & 35163.26 & \\
\hline & ${ }^{a} \mathrm{~V}_{2^{\oplus}}, \mathrm{cm}^{3} \cdot \mathrm{mol}^{-1}$ & 35032.73 & \pm 232.61 \\
\hline & ${ }^{b} \mathrm{~V}_{2^{\oplus}}, \mathrm{cm}^{3} \cdot \mathrm{mol}^{-1}$ & 35201.16 & \pm 67.49 \\
\hline & (ㅇ), g.mol-1 & 9.8991 & \pm 0.0673 \\
\hline \multicolumn{4}{|c|}{${ }^{*}$ Error in $\rho=4 \times 10^{-5} \mathrm{~g} \cdot \mathrm{cm}^{-3}$ and in $V_{2, \phi}$ is $\approx 0.05 \%$} \\
\hline
\end{tabular}

${ }^{b}$ Determined by Redlich $\rho=\rho_{1}+\Gamma c_{2}$, where $V_{2}^{\infty}=\frac{M_{2}-1000 \Gamma}{\rho_{1}}$ 
Table S2. Values of adiabatic compressibility and hydration number for OVA-NPG mixtures.

\begin{tabular}{|c|c|c|c|}
\hline $\mathrm{C}_{2} \times 10^{-4}, \mathrm{~mol} \cdot \mathrm{L}^{-1}$ & $n_{\text {solute }}(\mathrm{mol})$ & $\kappa_{\mathrm{s}} \times 10^{-5}, \mathrm{bar}^{-1}$ & ${ }_{\mathrm{a}, \mathrm{b}} n_{h}$ \\
\hline \multicolumn{4}{|c|}{$O V A+$ Water } \\
\hline 0 & 0.27754 & $c 4.475$ & \\
\hline 0.20 & $9.98 \mathrm{E}-08$ & 4.472 & 1918 \\
\hline 0.70 & 3.49E-07 & 4.468 & 1305 \\
\hline 1.20 & $5.99 \mathrm{E}-07$ & 4.463 & 1306 \\
\hline 1.50 & $7.49 \mathrm{E}-07$ & 4.459 & 1322 \\
\hline 2.30 & $1.15 \mathrm{E}-06$ & 4.451 & 1306 \\
\hline 2.99 & $1.50 \mathrm{E}-06$ & 4.444 & 1279 \\
\hline 3.49 & $1.75 \mathrm{E}-06$ & 4.438 & 1315 \\
\hline 3.99 & $2.00 \mathrm{E}-06$ & 4.433 & 1307 \\
\hline 5.99 & $2.99 \mathrm{E}-06$ & 4.413 & 1293 \\
\hline 7.98 & 3.99E-06 & 4.392 & 1287 \\
\hline \multirow[t]{4}{*}{9.98} & $4.99 \mathrm{E}-06$ & 4.372 & 1276 \\
\hline & ${ }^{a} n_{h}$ & 1300 & \pm 15 \\
\hline & ${ }^{b} n_{h}$ & 1276 & \pm 5 \\
\hline & $\partial \kappa_{s} / \partial x_{2}$ & $-5.7111 \mathrm{E}-08$ & $\pm 2,32 \mathrm{E}-10$ \\
\hline \multicolumn{4}{|c|}{$O V A+N P G$} \\
\hline 0 & 0,27622 & $c 4.474$ & \\
\hline 2.06 & $1.03 \mathrm{E}-06$ & 4.454 & 1232 \\
\hline 2.58 & $1.29 \mathrm{E}-06$ & 4.449 & 1232 \\
\hline 3.44 & $1.72 \mathrm{E}-06$ & 4.440 & 1237 \\
\hline 5.15 & $2.58 \mathrm{E}-06$ & 4.423 & 1241 \\
\hline 6.18 & $3.09 \mathrm{E}-06$ & 4.413 & 1233 \\
\hline 7.21 & $3.61 \mathrm{E}-06$ & 4.402 & 1238 \\
\hline 8.24 & 4.12E-06 & 4.390 & 1260 \\
\hline 9.27 & $4.64 \mathrm{E}-06$ & 4.381 & 1238 \\
\hline \multirow[t]{4}{*}{10.30} & $5.15 \mathrm{E}-06$ & 4.370 & 1255 \\
\hline & ${ }^{a} n_{h}$ & 1242 & \pm 10 \\
\hline & ${ }^{b} n_{h}$ & 1256 & \pm 8 \\
\hline & $\partial \kappa_{s} / \partial x_{2}$ & $-5.617 \mathrm{E}-08$ & $\pm 3.71 \mathrm{E}-10$ \\
\hline
\end{tabular}

*Error is $\leq 0.0001 \%$ for $\kappa_{\mathrm{s}}$ and $\leq 0.02 \%$ for $n_{h}$

${ }^{a}$ Estimated as $\overline{n_{h}}=\frac{\sum_{i=1}^{n}\left(n_{h}\right)_{i}}{n} \pm \sigma$

${ }^{b}$ Determined by $n_{h}=-\left(\partial \kappa_{s} / \partial x_{2}\right) / \kappa_{1}$

${ }^{c}$ As expected $\kappa_{1}($ water $) \approx \kappa_{1}($ water $+\mathrm{NPG})$, for rigid small molecular systems at low concentration 